\title{
A Correspondence Analysis of Fifty-Five Japanese Historical First-to Fifth-Year English-as-a-Foreign-Language Textbooks
}

\author{
Tomoo Asai ${ }^{1}$, Ryohei Honda ${ }^{2}$ and Kiyomi Watanabe ${ }^{3}$ \\ Fukuyama Heisei University \\ Fukuyama, Japan \\ ${ }^{1}$ https://orcid.org/0000-0003-2627-2883 \\ ${ }^{2}$ https://orcid.org/0000-0001-7488-2403 \\ 3https://orcid.org/0000-0002-6520-8115 \\ Toshiaki Ozasa \\ Hiroshima University (Professor Emeritus) \\ Higashi-Hiroshima, Japan \\ https://orcid.org/0000-0002-5358-2660
}

\begin{abstract}
The present paper aims to quantitatively analyze the features of fifty-five Japanese historical English-as-a-Foreign-Language textbooks, Books $1-5$, by using a correspondence analysis, focusing on their homogeneities / differences, and to compare the results with those of the correspondence analyses of the Book-1, Book- 3 and Book- 5 textbooks. The following were the obtained results. First, the correspondence analysis results proved capable of differentiating the features of the fifty-five historical textbooks. In particular, the bipolar map indicated that the two dimensions, difficult (+) vs. easy (-) (Dim 1) axis and artificial- (+) vs. naturalsounding (-) (Dim 2) axis contributed to differentiating their interrelationships. Second, their inter-relationship was explained 80.4 percent by the seven dimensions, i.e., (1) difficult/easy texts (Dim 1), (2) artificial-/naturalsounding discourse (Dim 2), (3) dialogue-/passage-based textbooks (Dim 3), (4) teacher-/non teacher-dominance (Dim 4), (5) strictly / loosely controlled (Dim 5), (6) redundant/concise (Dim 6) and (7) connected/disconnected (Dim-7). Third, the differences of the fifty-five Books-1-5 textbooks were explained by the same dimensions as those of the Book-3 and Book-1 results up to the seventh dimension. The results of the present correspondence analysis were graphically represented by two methods, coordinate (bipolar) representation and dendrogram. Concerning the theoretical implications and practical use of the present study, it was proved that CA is a powerful tool for the quantitative analysis and evaluation of EFL textbooks and that difficulty vs. easiness and artificial-sounding vs. natural-sounding are useful viewpoints for EFL teachers and educators in describing and grasping EFL textbooks.
\end{abstract}

Keywords: correspondence analysis; English as a foreign language; historical textbooks; coordinate representation; dendrogram 


\section{Introduction}

Following several qualitative and quantitative analyses of Japanese historical English-as-a-foreign-language (Henceforth EFL) textbooks such as Ozasa (2003), Ozasa 2005) and Ozasa \& Erikawa (Eds.) (2004), the correspondence analysis (Henceforth CA) of their corpora started in Japan with Sakamoto, Watanabe, and Ozasa (2017), which, computing a CA using seven historical and current textbooks, identified four explaining dimensions, i.e., (1) natural vs. drill-centered (Dim 1), (2) concise vs redundant (Dim 2), (3) difficult vs. easy (Dim 3) and (4) monologue vs. multilogue (Dim 4). Watanabe, Asai, and Ozasa (2017) also computed the same type of CA-based textual analysis, using seven historical or current EFL textbooks, identifying four explaining categories, i.e., (1) easy vs. difficult (Dim 1), (2) story vs. collection (Dim 2), concise vs. redundant (Dim 3) and (4) monologue vs. multilogue (Dim 4). Both of the two studies (Sakamoto et al.,2017, Watanabe., 2017) concluded that CA was a useful tool for interpreting and diagnosing the features of the EFL textbooks.

In Honda, Watanabe and Ozasa (2017), the same type of CA-based multivariate analysis was computed using ten historical or current Book-1 EFL textbooks, identifying five explaining dimensions, i.e., (1) difficult vs. easy (Dim 1), (2) drillcentered vs. natural (Dim 2), (3) multi-viewpoints vs. single viewpoint (Dim 3) and (4) redundant vs. concise (Dim 4). The results also revealed that the bipolar map comprised of the two major dimensions successfully classified the ten textbooks into four groups and that it was only Dim 1 or difficult vs. easy texts that differentiated the two major groups. Ozasa, Kawamura, Umamoto and Matsuoka (2018) also computed a CA-based textual analysis of five Japanese historical or current EFL textbooks, with the same aim as in the above analyses. The results of this multivariate analysis identified four explaining dimensions, i.e., (1) natural vs. drill-centered (Dim 1), (2) easy vs. difficult (Dim 2), (3) focused vs. unfocused (Dim 3) and (4) varied vs. single practice (Dim 4). These findings were displayed 100 percent by a four-dimension-based radar gram and 64.1 percent by a bipolar coordinate representation, which was comprised of a horizontal axis and a vertical axis.

Honda, Asai, Watanabe and Ozasa (2018) computed the same type of CA-based multivariate analysis of eighteen Japanese historical or current Book-1 EFL textbook corpora under the same scheme as in the above CAs. The interpretation of this textual analysis result identified seven explaining dimensions, i.e., (1) difficult vs. easy (Dim 1), (2) natural- vs. artificial-sounding (Dim 2), (3) passagevs. dialogue-based (Dim 3), (4) teacher dominance vs. non teacher dominance (Dim 4), (5) strictly- vs. loosely-controlled (Dim 5), (6) concise vs. redundant (Dim 6) and (7) connected vs. disconnected (Dim 7).

Asai, Honda, Watanabe and Ozasa (2019) computed the same type of multivariate analysis of categorical data, using seventeen Japanese Book-3 EFL textbook corpora, both historical and current, with the same aim as in the above analyses. The interpretation of this textual analysis result successfully identified seven explaining dimensions, i.e., (1) difficult vs. easy (Dim 1), (2) natural- vs. artificialsounding (Dim 2), (3) dialogue- vs. passage-based (Dim 3), (4) teacher dominance vs. non teacher dominance (Dim 4), (5) strictly- vs. loosely-controlled (Dim 5), (6) redundant vs. concise (Dim 6) and (7) connected vs. disconnected (Dim 7). In 
particular, it was interesting to note that the features of the seventeen Book-3 textbooks were explained by the same dimensions of the Book-1 result up to Dim 7. It was also reported that the interrelationships of the seventeen variants were successfully explained by the two graphic representations of the analysis results, i.e., the bipolar coordinate representation and the CA-based dendrogram based on all of the sixteen dimensions.

Following Asai et al. (2019), Honda, Asai, Watanabe and Ozasa (2019) also computed the same type of CA under the same scheme as the above ones, using twelve historical and one current EFL textbooks, with an aim to identify features/categories that differentiate the textbooks in focus and to compare the differentiators among the Book-1, Book-3 and Book-5 results. This analysis identified four dimensions: speech-oriented vs. exposition-oriented discourse (Dim 1), easy vs. difficult texts (Dim 2), variety-rich vs. variety-poor (Dim 3), and teacher-assistance vs. non-teacher-assistance (Dim 4).

Based on their own CA findings as these, Honda et al. (2019) compared the differentiating categories among the results of the Book-1, Book-3 and Book-5 CAs, as in the following tables (Table 1) (Honda et al., 2019). This comparison revealed several interesting points regarding the holistic approach to the CAbased multivariate analysis of all of the Japanese historical EFL textbooks covering all of the volumes (years) of the books. It was found that the nature of the dimensions identified proved to be very similar or basically the same among the three solutions, i.e., the Book-1, Book-3 and Book-5 solution, which means that the results of the three independently conducted CAs yielded almost the same results, i.e., almost the same dimensions in almost the same order.

Table 1: Dimensions of 3 CAs

\begin{tabular}{|c|c|c|c|}
\hline & Book-1 & Book-3 & Book-5 \\
\hline $\operatorname{Dim} 1$ & difficult vs. easy texts & difficult vs. easy texts & $\begin{array}{l}\text { speech-oriented vs. } \\
\text { exposition-oriented } \\
\text { discourse }\end{array}$ \\
\hline $\operatorname{Dim} 2$ & $\begin{array}{l}\text { natural-sounding vs. } \\
\text { artificial-sounding } \\
\text { discours }\end{array}$ & $\begin{array}{l}\text { natural-sounding vs. } \\
\text { artificial-sounding } \\
\text { discourse }\end{array}$ & easy vs. difficult texts \\
\hline $\operatorname{Dim} 3$ & $\begin{array}{l}\text { passage-based vs. } \\
\text { dialogue-based texts }\end{array}$ & $\begin{array}{l}\text { dialogue-based vs. } \\
\text { passage-based texts }\end{array}$ & $\begin{array}{l}\text { variety-rich vs. variety- } \\
\text { poor textbooks }\end{array}$ \\
\hline $\operatorname{Dim} 4$ & $\begin{array}{l}\text { teacher dominance vs. } \\
\text { non teacher dominance }\end{array}$ & $\begin{array}{l}\text { teacher dominance vs. } \\
\text { non teacher dominance }\end{array}$ & $\begin{array}{l}\text { teacher assistance } \\
\text { vs.non-teacher } \\
\text { assistance }\end{array}$ \\
\hline $\operatorname{Dim} 5$ & $\begin{array}{l}\text { strictly-controlled vs. } \\
\text { loosely-controlled texts }\end{array}$ & $\begin{array}{l}\text { strictly controlled vs. } \\
\text { loosely controlled texts }\end{array}$ & \\
\hline $\operatorname{Dim} 6$ & $\begin{array}{l}\text { concise vs. redundant } \\
\text { texts }\end{array}$ & $\begin{array}{l}\text { redundant vs. concise } \\
\text { texts }\end{array}$ & \\
\hline $\operatorname{Dim} 7$ & $\begin{array}{l}\text { connected vs. } \\
\text { disconnected contents }\end{array}$ & $\begin{array}{l}\text { connected vs. } \\
\text { disconnected contents }\end{array}$ & \\
\hline
\end{tabular}

(Honda et al., 2019)

This could also suggest that this approach, i.e., CA-based multivariate textual analysis, could be applied in principle to the interpretation and classification of 
the other volumes (years) such as Book-2 and Book-4, and that their resultant dimensions could be explained by the same set of categories/features as those of the Book-1, Book-3 and Book-5 CAs, as graphically represented in Table 2.

Table 2: Theoretical framework of the present CA

\begin{tabular}{|c|c|c|c|c|c|}
\hline Dim & Book-1 & Book-2 & Book-3 & Book-4 & Book-5 \\
\hline 1 & difficult/easy & difficult/easy & difficult/easy & difficult/easy & $\begin{array}{l}\text { speech/exposition- } \\
\text { oriented }\end{array}$ \\
\hline 2 & $\begin{array}{l}\text { natural-/artificial- } \\
\text { sounding }\end{array}$ & $\begin{array}{l}\text { natural-/artificial- } \\
\text { sounding }\end{array}$ & $\begin{array}{l}\text { natural-/artificial- } \\
\text { sounding }\end{array}$ & $\begin{array}{l}\text { natural-/artificial- } \\
\text { sounding }\end{array}$ & easy/difficult \\
\hline 3 & \begin{tabular}{|l|} 
passage-/dialogue- \\
based
\end{tabular} & $\begin{array}{l}\text { passage-/dialogue- } \\
\text { based }\end{array}$ & $\begin{array}{l}\text { dialogue/passage- } \\
\text { based }\end{array}$ & $\begin{array}{l}\text { dialogue/passage- } \\
\text { based }\end{array}$ & $\begin{array}{l}\text { variety- } \\
\text { rich/variety-poor }\end{array}$ \\
\hline 4 & $\begin{array}{l}\text { teacher } \\
\text { dominance/non td }\end{array}$ & $\begin{array}{l}\text { teacher } \\
\text { dominance/non td }\end{array}$ & $\begin{array}{l}\text { teacher } \\
\text { dominance/non td }\end{array}$ & $\begin{array}{l}\text { teacher } \\
\text { dominance/non td }\end{array}$ & $\begin{array}{l}\text { teacher } \\
\text { assistance/non ta }\end{array}$ \\
\hline 5 & $\begin{array}{l}\text { strictly/loosely } \\
\text { controlled }\end{array}$ & $\begin{array}{l}\text { strictly/loosely } \\
\text { controlled }\end{array}$ & $\begin{array}{l}\text { strictly/loosely- } \\
\text { controlled }\end{array}$ & $\begin{array}{l}\text { strictly/loosely- } \\
\text { controlled }\end{array}$ & \\
\hline 6 & concise/redundant & concise/redundant & $\begin{array}{l}\text { redundant/concis } \\
\mathrm{e}\end{array}$ & redundant/concise & \\
\hline 7 & $\begin{array}{l}\text { connected/ } \\
\text { disconnected }\end{array}$ & $\begin{array}{l}\text { connected/ } \\
\text { disconnected }\end{array}$ & $\begin{array}{l}\text { connected/ } \\
\text { disconnected }\end{array}$ & $\begin{array}{l}\text { connected/ } \\
\text { disconnected }\end{array}$ & \\
\hline
\end{tabular}

In practical terms, however, the use of these identified dimensions could not be so operational in the classifications of the Book-2 or Book-4 EFL textbooks as in those of the Book-1, Book-3 and Book- 5 textbooks since there were no values of these textbooks available in terms of these dimensions. Furthermore, even the data of the Book-1, Book-3 and Book- 5 textbooks would be limited in use for their classification and quantitative comparison since their statistic data were obtained through the independent computation using different sets of textbook data. "Clearly, this was not an ideal solution as it had been expected since all of the textbooks, Book-1, Book-3, and Book-5 could not be interpreted and classified from one set of perspectives.

To solve this problem, new attempts have to be made to develop a new method, technique or model for the CA with a large corpus" (Honda et al., 2019, p. 97). The basic hypothesis in the present CA, based on these considerations concerning the results of the previous analyses, is that present fifty-five historical EFL textbooks could be explained and classified by one set of seven categories/features and that the seven categories would be the same as those identified in the CAs of the Book-1, Book-3 and Book-5 textbooks.

The present CA, motivated by the above hypothesis and considerations, aims to statistically classify relatively large corpora of fifty-five Japanese historical Book1 to -5 EFL textbooks from a broader perspective. Through this multivariate textual analysis, educators and/or teachers interested in EFL teaching would have chances to understand the key concepts that affects English language teaching in the textbooks and classrooms in and outside Japan, and make good use of them in their classroom practice. 


\section{Aim}

The present paper aims to quantitatively describe the features of fifty-five Japanese historical EFL textbooks (eleven sets comprised of five volumes, i.e., Book-1, Book-2, Book-3, Book-4 and Book-5 textbooks) and to statistically classify them based on their differences described in the results of the CA computed.

The following three research questions (RQs) were set in the present analysis:

(1) How similar / different in contents are the fifty-five Japanese historical EFL textbooks (Books 1-5) to / from each other?

(2) What kinds of dimensions explain the homogeneities / differences among the fifty-five textbooks?

(3) How similar / different are the solution of the fifty-five Japanese first- to fifth-year EFL textbooks to / from those of their first-, third- and fifth-year textbooks?

The present CA is primarily concerned with and focused on what kinds of criteria explain the homogeneity / differences among the fifty-five textbooks and on how they are related to the dimensions identified in the previous results of the Book-1, Book-3 and Book-5 CA, in terms of the nature of their features.

The textbooks used in the present CA were eleven sets of historical EFL textbooks, totalling fifty-five volumes, published during the period from 1867 to 1953 . The following are the titles and bibliographical data of the fifty-five textbooks, which are primarily based on Ozasa and Erikawa (Eds.) (2004). For more detailed information on the authors and characteristic features of these textbooks, refer to Ozasa and Erikawa (Eds.) (2004) and Honda et al. (2018).

(1) Standard Choice Readers, 1-5 (Shobido Editorial, 1902, Shobido, 5 Vols.) (Henceforth Choice-1 to -5.)

(2) English Readers: The High School Series, 1-5 (Education Department, Japan [W. Dening], 1887-88, Education Department Publishing, Japan, 6 Vols.) (Henceforth Dening-1 to -5.)

(3) New English Drill Books, 1-5 (Kenjiro Kumamoto, 1907, Kaiseikan, 5 Vols.) (Henceforth Drill-1 to -5.)

(4) The Globe Readers, 1-5(Yoshisaburo Okakura, 1907, Dainippon Tosho, 5 Vols. (Henceforth Globe-1 to -5.)

(5) New Jack and Betty: English Step by Step, 1-3 (K. Hagiwara, M. Inamura \& K. Takezawa, 1951, Kairyudo, 1-3Vols) (Henceforth Jack\&Betty-1 to -3)). New High School English: Step by Step, 1-2 (K. Hagiwara, M. Inamura \& K. Takezawa, 1953, Kairyudo, 3 Vols.) (Henceforth Jack\&Betty-4 to -5.)

(6) New National Readers, 1-5 (C. J. Barnes, 1883-84, A. S. Barnes \& Co., 5 Vols.) (Henceforth National-1 to -5.)

(7) Girls' Pacific Readers, 1-5 (Torajiro Sawamura, 1939, Kairyudo, 5 Vol.) (Henceforth Pacific-1 to -5.)

(8) The Standard English Readers, 1-5 (H. E. Palmer, 1927, Institute for Research in English Teaching, Japan, 5 Vols.) (Henceforth Standard( $p$ )-1 to -5.) 
(9) The Standard English Readers, 1-5 (Tsuneta Takehara, 1932, Taishukan, 5 Vols.) (Henceforth Standard(t) -1 to -5 .)

(10) Girls' New Taisho Readers, 1-5 (Umeko Tsuda \& Kenjiro Kumamoto, 1916, Tokyo Kaiseikan, 5 Vols.) (Henceforth Taisho-1 to -5.)

(11) Sanders' Union Readers, 1-5 (Charles Walton Sanders, 1861-67, Ivison, Blakeman, Taylor \& Co., 5 Vols.) (Henceforth Union-1 to -5.)

Among the above eleven sets, (5) Jack\&Betty-4 to -5 needs some supplementary explanation. In (5), there were no Books 4 nor 5 of New Jack and Betty available, since it was a junior high school textbook consisting of three volumes only, Book1, Book-2 and Book-3. To solve this problem, newly added as the replacements or supplements of New Jack and Betty, 4 and 5 were New High School English: Step by Step, 1 and 2, two senior high school textbook volumes, which were authored by the same authors and published by the same publisher as those of New Jack and Betty series, (abbreviated as Jack\&Betty-4 \&-5).

It has also to be noted concerning the selection of the textbooks for the present CA that the two textbooks used in the previous ones, i.e., Seisoku- 1 to -5 and Sunshine1 to -5 were excluded from the present corpora. This judgment was based on the experience in the CA of the seventeen historical textbooks (Asai et al., 2019), which resulted in an extremely skewed distribution, making its interpretation difficult, due to the extremely strong negative influence of Seisoku-3. Sunshine-1 to -5 were also excluded from the CA corpora since these current textbooks were essentially different in nature from the other historical textbooks. This decision was also made by the present researchers' wish to reduce the number of the variants as much as possible.

\section{Method}

The present study employed a one-way CA model with fifty-five categorical variants, in order to explore the interrelationships of the Japanese historical Book1 to -5 EFL textbooks and their explaining criteria.

First, a contingency table consisting of the fifty-five textbooks (row) and the frequency of their most frequently used 100 words (column) was prepared as a basic datum for the present CA. This is strictly a word-frequency table for each textbook, which was made using a vocabulary processing tool. In this cross tabulation table the most frequent 100 words (only content words and function words counted) were picked up from the frequency list and their frequency values were placed for each of the textbooks. Then, using the this categorical datum of the cross tabulation table, a CA, a type of multivariate analysis, was computed by using College Analysis, a statistics tool developed by M. Fukui.

In computing the present $\mathrm{CA}$ and interpreting its results, some of the ideas and techniques used and/or described in the following books and papers were consulted for reference where they were deemed relevant to the purpose of the present analysis. They were: Beh and Lombardo (2014), Clausen (1998), Fukui (2011), Fukui and Watanabe (2019a), Fukui and Watanabe (2019b), Greenacre (2017), Greenacre (2010), Tabata (2005), Takahashi (2018), Tono (2000), Uenish 
(2018), Van de Geer (1993), Watanabe and Fukui (2018a) and Watanabe and Fukui (2018b) (Honda, et al., 2019).

\section{Results and discussion}

Table 3 shows the basic statistics of the present CA, i.e., the eigenvalues, correlation coefficients, contribution rates and cumulative contribution rates of the analysis. As the contribution rates indicate $i$, the fifty-five categorical variants (textbooks) were explained $46.9 \%$ by Dim 1, 12.0\% by Dim 2, 6.00\% by Dim 3, $5.00 \%$ by $\operatorname{Dim} 4,4.10 \%$ by $\operatorname{Dim} 5,3.60 \%$ by $\operatorname{Dim} 6$ and $2.90 \%$ by $\operatorname{Dim} 7$, the cumulative contribution rate being $80.40 \%$ on Dim 7 . This means that Dim 1 is the most powerful discriminator that explains almost half of the features identified and that the seven Dims should be considered in the interpretation of the present results.

Table 3: Basic CA Data, 55 Textbooks (Books 1-5)

\begin{tabular}{|c|c|c|c|c|c|c|}
\hline & Dim 1 & $\operatorname{Dim} 2$ & $\operatorname{Dim} 3$ & Dim 4 & Dim 5 & Dim 6 \\
\hline Eigenvalue & 0.102 & 0.026 & 0.013 & 0.011 & 0.009 & 0.008 \\
\hline Correlation & 0.32 & 0.162 & 0.115 & 0.104 & 0.095 & 0.088 \\
\hline Contribution rate & 0.469 & 0.12 & 0.06 & 0.05 & O.041 & 0.036 \\
\hline \multirow[t]{2}{*}{$\begin{array}{l}\text { Cumulative contribution } \\
\text { rate }\end{array}$} & 0.469 & 0.589 & 0.649 & 0.699 & 0.739 & 0.775 \\
\hline & Dim 7 & Dim 8 & Dim 9 & Dim 10 & Dim 11 & Dim 12 \\
\hline Eigenvalue & 0.006 & 0.005 & 0.004 & 0.004 & 0.004 & 0.003 \\
\hline Correlation & 0.08 & 0.073 & 0.066 & 0.062 & 0.06 & 0.056 \\
\hline Contribution rate & 0.029 & 0.025 & 0.02 & 0.018 & 0.016 & 0.014 \\
\hline \multirow[t]{2}{*}{\begin{tabular}{|l|}
$\begin{array}{l}\text { Cumulative contribution } \\
\text { rate }\end{array}$ \\
\end{tabular}} & 0.804 & 0.829 & 0.848 & 0.866 & 0.882 & 0.897 \\
\hline & Dim 13 & $\operatorname{Dim} 14$ & Dim 15 & Dim 16 & Dim 17 & Dim 18 \\
\hline Eigenvalue & 0.002 & 0.002 & 0.002 & 0.002 & 0.002 & 0.001 \\
\hline Correlation & 0.049 & 0.048 & 0.044 & 0.043 & 0.039 & 0.036 \\
\hline Contribution rate & 0.011 & 0.01 & 0.009 & 0.008 & 0.007 & 0.006 \\
\hline \multirow[t]{2}{*}{$\begin{array}{l}\text { Cumulative contribution } \\
\text { rate }\end{array}$} & 0.908 & 0.918 & 0.927 & 0.935 & 0.942 & 0.948 \\
\hline & Dim 19 & $\operatorname{Dim} 20$ & $\operatorname{Dim} 21$ & $\operatorname{Dim} 22$ & $\operatorname{Dim} 23$ & Dim 24 \\
\hline Eigenvalue & 0.001 & 0.001 & 0.001 & 0.001 & 0.001 & 0.001 \\
\hline Correlation & 0.032 & 0.03 & 0.03 & 0.029 & 0.028 & 0.026 \\
\hline Contribution rate & 0.005 & 0.004 & 0.004 & 0.004 & 0.004 & 0.003 \\
\hline \multirow[t]{2}{*}{\begin{tabular}{|l|}
$\begin{array}{l}\text { Cumulative contribution } \\
\text { rate }\end{array}$ \\
\end{tabular}} & 0.953 & 0.957 & 0.961 & 0.965 & 0.968 & 0.971 \\
\hline & $\operatorname{Dim} 25$ & $\operatorname{Dim} 26$ & $\operatorname{Dim} 27$ & $\operatorname{Dim} 28$ & $\operatorname{Dim} 29$ & Dim 30 \\
\hline Eigenvalue & 0.001 & 0.001 & 0.001 & 0 & 0 & $\mathrm{O}$ \\
\hline Correlation & 0.025 & 0.024 & 0.022 & 0.021 & 0.021 & 0.019 \\
\hline Contribution rate & 0.003 & 0.003 & 0.002 & 0.002 & 0.002 & 0.002 \\
\hline \multirow[t]{2}{*}{$\begin{array}{l}\text { Cumulative contribution } \\
\text { rate }\end{array}$} & 0.974 & 0.977 & 0.979 & 0.981 & 0.983 & 0.985 \\
\hline & $\operatorname{Dim} 31$ & Dim 32 & $\operatorname{Dim} 33$ & Dim 34 & $\operatorname{Dim} 35$ & Dim 36 \\
\hline Eigen & $\mathrm{O}$ & o & $\mathrm{O}$ & $\mathrm{O}$ & $\mathrm{O}$ & $\mathrm{O}$ \\
\hline Correlation & 0.019 & 0.018 & 0.017 & 0.016 & 0.015 & 0.015 \\
\hline Contribution rate & 0.002 & 0.001 & 0.001 & 0.001 & 0.001 & 0.001 \\
\hline \multirow[t]{2}{*}{$\begin{array}{l}\text { Cumulative contribution } \\
\text { rate }\end{array}$} & 0.986 & 0.988 & 0.989 & 0.99 & 0.991 & 0.992 \\
\hline & Dim 37 & Dim 38 & Dim 39 & $\operatorname{dim} 40$ & $\operatorname{Dim} 41$ & Dim 42 \\
\hline Eigenvalue & $\mathrm{O}$ & $\mathrm{O}$ & $\mathrm{O}$ & $\mathrm{O}$ & $\mathrm{O}$ & $\mathrm{O}$ \\
\hline Correlation & 0.015 & 0.014 & 0.013 & 0.012 & O.011 & 0.011 \\
\hline Contribution rate & 0.001 & 0.001 & 0.001 & 0.001 & 0.001 & 0.001 \\
\hline \multirow[t]{2}{*}{$\begin{array}{l}\text { Cumulative contribution } \\
\text { rate }\end{array}$} & 0.993 & 0.994 & 0.995 & 0.996 & 0.996 & 0.997 \\
\hline & $\operatorname{Dim} 43$ & $\operatorname{Dim} 44$ & $\operatorname{Dim} 45$ & Dim 46 & $\operatorname{Dim} 47$ & $\operatorname{Dim} 48$ \\
\hline Eigenvalue & 0 & o & $\mathrm{O}$ & $\mathrm{O}$ & 0 & $\mathrm{O}$ \\
\hline Correlation & 0.01 & 0.01 & 0.01 & 0.009 & 0.008 & 0.009 \\
\hline Contribution rate & $\mathrm{O}$ & $\mathrm{O}$ & $\mathrm{O}$ & $\mathrm{O}$ & $\mathrm{O}$ & $\mathrm{O}$ \\
\hline \multirow[t]{2}{*}{$\begin{array}{l}\text { Cumulative contribution } \\
\text { rate }\end{array}$} & 0.997 & 0.998 & 0.998 & 0.999 & 0.999 & 0.999 \\
\hline & $\operatorname{Dim} 49$ & Dim 50 & Dim 51 & Dim 52 & Dim 53 & Dim 54 \\
\hline Eigenvalue & $\mathrm{O}$ & $\mathrm{O}$ & $\mathrm{O}$ & $\mathrm{O}$ & $\mathrm{O}$ & $\mathrm{O}$ \\
\hline Correlation & 0.008 & 0.007 & 0.006 & 0.004 & 0 & 0 \\
\hline Contribution rate & 0 & of & $\mathrm{O}$ & 0 & of & $\mathrm{O}$ \\
\hline $\begin{array}{l}\text { Cumulative contribution } \\
\text { rate }\end{array}$ & 1 & 1 & 1 & 1 & 1 & 1 \\
\hline
\end{tabular}


Table 4 shows the values of the fifty-five textbooks on Dim 1 . As it is clear in Table 4, on Dim 1, the value is the highest for Dening-5 (1.26), the second highest for National-5 (1.053) and the third highest for Globe-5 (1.023), while it is the lowest for JackEBetty-1 (-2.411), the second lowest for Pacific-1 (-2.374) and the third lowest for Drill-1 (-2.312). In decreasing order, the fifty-five textbooks were: Dening-5 > National-5 $>$ Globe-5 $>$ Choice-5 $>$ Union-5 $>$ Standard(p)-2 $>$ Dening-3 $>$ Union-4 $>$ Choice-4 $>$ Dening-4 ..... Taisho-2 $>$ Standard $(t)-1>$ Globe-1 $>$ National-1 $>$ Choice-1 $>$ Standard $(p)-1>$ Taisho-1 $>$ Drill-1 > Pacific-1 > JackEBetty-1.

The difference of the values among the fifty-five textbooks on Dim 1 could best be explained by the category of difficult (+) vs. easy (-) texts. As it is clear in the following examples, in Dening-5 (the highest) and National-5 (the second highest) and the other high-scoring ones, all the texts sound difficult. In contrast, in JackEBetty-1 (the lowest), Pacific-1 (the second lowest) and the other low-scoring ones, the texts sound all easy.

Table 4: Values on Dim 1

\begin{tabular}{|l|r|l|r|l|r|l|r|}
\hline & Dim 1 & & Dim 1 & & \multicolumn{1}{c|}{ Dim 1 } & & Dim 1 \\
\hline Dening-5 & 1.26 & Pacific-5 & 0.717 & Standard(t)-2 & 0.263 & Taisho-2 & -0.878 \\
\hline National-5 & 1.053 & Globe-3 & 0.713 & Pacific-4 & 0.244 & Standard(t)-1 & -1.016 \\
\hline Globe-5 & 1.023 & Dening-1 & 0.712 & National-3 & 0.214 & Globe-1 & -1.398 \\
\hline Choice-5 & 0.998 & Standard(t)-4 & 0.697 & National-4 & 0.214 & National-1 & -1.413 \\
\hline Union-5 & 0.949 & Standard(p)-5 & 0.692 & Taisho-4 & 0.168 & Choice-1 & -1.573 \\
\hline Standard(p)-2 & 0.908 & Jack\&Betty-5 & 0.674 & Jack\&Betty-3 & 0.009 & Standard(p)-1 & -1.722 \\
\hline Dening-3 & 0.857 & Drill-5 & 0.664 & Pacific-3 & -0.009 & Taisho-1 & -2.225 \\
\hline Union-4 & 0.849 & Taisho-5 & 0.63 & Taisho-3 & -0.009 & Drill-1 & -2.312 \\
\hline Choice-4 & 0.819 & Drill-4 & 0.572 & Choice-2 & -0.034 & Pacific-1 & -2.374 \\
\hline Dening-4 & 0.81 & Standard(p)-4 & 0.562 & National-2 & -0.131 & Jack\&Betty-1 & -2.411 \\
\hline Dening-2 & 0.807 & Jack\&Betty-4 & 0.497 & Pacific-2 & -0.363 & & \\
\hline Standard(t)-5 & 0.799 & Choice-3 & 0.396 & Union-1 & -0.388 & & \\
\hline Globe-4 & 0.774 & Union-3 & 0.363 & Jack\&Betty-2 & -0.589 & & \\
\hline Standard(t)-3 & 0.74 & Union-2 & 0.345 & Drill-2 & -0.794 & & \\
\hline Standard(p)-3 & 0.722 & Drill-3 & 0.341 & Globe-2 & -0.794 & & \\
\hline
\end{tabular}

For example, when the following two pieces taken from the two contrasting textbooks, Dening-5 (the most difficult) and JackEBetty-1 (the easiest), are compared, it is obvious that Dening- 5 uses more difficult vocabulary and grammar in the texts and so its readability is contrastively high, while Jack\&Betty-1 favors easier vocabulary and grammar, making its readability lower. For this reason, the Dim 1 was termed difficult (+) vs. easy texts (-), just as in the Book-1 (Honda et al., 2018) and Book-3 (Asai et al., 2019) results. The contribution rate of Dim 1 was 0.469 , covering the $46.9 \%$ of the whole contribution.

To verify the accuracy of this CA estimation, the readability of the fifty-five textbooks was actually measured using a readability measuring tool developed specifically for the Japanese educational context, Ozasa-Fukui Year Level, Ver. $3.5 n h n c 1-6^{1}$ and the results were compared with the present CA results. The

${ }^{1}$ The development of Ozasa-Fukui Year Level, Ver. 3.5nhnc1-6 was financially supported by the Grant-in-aid for Scientific Research (KAKENHI), Japan Society for the Promotion 
function equation (NewDiff) of Ozasa-Fukui Year Level, Ver. 3.5nhnc1-6 was as follows, where Words stands for number of words in a sentence, Syllables number of syllables in a word, WordDiff difficulty of a word, and IdiomDiff difficulty of an idiom, and its prediction rate turned out to be .8912 (Ozasa, Watanabe, \& Fukui, 2016, p. 392).

NewDiff $=5.2565^{*} \exp \left(-19.1656^{*} 0.4398^{\wedge}\right.$ Diff $)+1\left(\mathrm{r}^{\wedge} 2=0.8912\right)$

Diff $=0.0924 *$ Words $+0.5862 *$ Syllables $+1.8296 *$ WordDiff $+0.0615 *$ IdiomDiff -0.3073

$$
\left(\mathrm{r}^{\wedge} 2=0.4986\right)
$$

Words: number of words in a sentence

Syllables: number of syllables in a word

WordDiff: difficulty of a word

IdiomDiff: difficulty of an idiom

In this system, WordDiff was defined as the year of a textbook in which a particular word appeared for the first time and IdiomDiff as the year of a textbook in which a particular idiom appeared for the first time. Its prediction rate $\left(\mathrm{r}^{\wedge} 2\right)$ proved to be .8912 , which the present authors believe was a satisfactorily high validity value. (Ozasa, Watanabe, \& Fukui, 2016, p. 392; Ozasa et al., 2016, p. 392; Honda, et al., 2018; Asai, et al., 2019; Honda et al., 2019).

Table 5 shows the readability values of the fifty-five textbooks as measured by Ozasa-Fukui Year Level, Ver. 3.5nhnc1-6. In order to measure the degree of correspondence between the two kinds of values, a rank correlation coefficient (Spearman's $\rho$ ) was computed between the Dim 1 estimation and the Ozasa-Fukui Year Level measurement. The correlation coefficient computed proved to be 0.878 $(p<.005)$, a satisfactorily high correlation. This means that the computed correlation was as high as the same kind of coefficient in the CA with the eighteen Book-1 textbooks, 804 ( $\mathrm{p}<.001)$ (Honda et al., 2018).

of Science (JSPS), 2007-9, Basic Research (C)(1)19520535. Its program copy right is registered in Japan. It is open for access for free on the net. 
Table 5: Readability Measured by OFYL

\begin{tabular}{|l|r|l|r|l|r|l|r|}
\hline & \multicolumn{1}{|c|}{ OFYL } & & \multicolumn{1}{c|}{ OFYL } & & OFYL & & OFYL \\
\hline Union-5 & 8.05 & Dening-1 & 6.62 & Drill-4 & 5.45 & National-1 & 3.39 \\
\hline Pacific-5 & 7.69 & National-4 & 6.61 & National-3 & 5.32 & Choice-1 & 3.33 \\
\hline Dening-5 & 7.62 & Standard(p)-5 & 6.56 & Choice-2 & 5.31 & Globe-1 & 3.26 \\
\hline Choice-5 & 7.49 & Standard(t)-4 & 6.51 & Taisho-4 & 5.3 & Jack\&Betty-2 & 3.21 \\
\hline Choice-4 & 7.44 & Standard(p)-2 & 6.50 & Pacific-3 & 5.03 & Standard(t)-1 & 3.16 \\
\hline Union-4 & 7.41 & Taisho-5 & 6.42 & Standard(t)-2 & 4.42 & Standard(p)-1 & 3.12 \\
\hline National-5 & 7.39 & Drill-5 & 6.41 & Globe-2 & 4.00 & Taisho-1 & 3.04 \\
\hline Dening-4 & 7.21 & Union-2 & 6.40 & Jack\&Betty-4 & 3.99 & Pacific-1 & 2.52 \\
\hline Dening-2 & 7.10 & Standard(p)-4 & 6.39 & National-2 & 3.98 & Drill-1 & 1.91 \\
\hline Union-1 & 6.99 & Choice-3 & 6.04 & Taisho-3 & 3.91 & Jack\&Betty-1 & 1.58 \\
\hline Dening-3 & 6.94 & Standard(p)-3 & 5.95 & Pacific-2 & 3.89 & & \\
\hline Standard(t)-5 & 6.89 & Globe-4 & 5.92 & Jack\&Betty-3 & 3.75 & & \\
\hline Union-3 & 6.71 & Jack\&Betty-5 & 5.91 & Drill-3 & 3.69 & & \\
\hline Globe-3 & 6.63 & Standard(t)-3 & 5.91 & Taisho-2 & 3.51 & & \\
\hline Globe-5 & 6.63 & Pacific-4 & 5.86 & Drill-2 & 3.40 & & \\
\hline
\end{tabular}

I could be argued that the indirect estimation of the present CA of the fifty-five corpora are accurate enough to satisfy the goal of the present study (Honda et al., 2017; Honda et al., 2018; Asai et al., 2019; Honda et al., 2019). This level of accuracy could be generalized to the estimations of the other six Dims (Dims 2, 3, 4, 5, 6 and 7). This estimation could also be reinforced by the fact that the top five of the most difficult textbooks were all Book-5 textbooks, i.e., textbooks for the fifth-year students, while the top five of the easiest textbooks were all Book-1 textbooks, i.e., textbooks for the first-year students.

For this reason, Dim 1 was termed difficult (+) vs. easy (-) texts, just as in the Book1 CA results (Honda et al., 2018), the Book-3 CA results (Asai et al., 2019) and the Book-5 CA results (Honda et al., 2019). The contribution rate of Dim 1 was 0.469, covering the $46.9 \%$, almost half of the whole contribution.

Table 6: Values on Dim 2

\begin{tabular}{|l|r|l|r|l|r|l|r|}
\hline & Dim 2 & & Dim 2 & & Dim 2 & & Dim 2 \\
\hline Pacific-1 & 1.885 & National-5 & 0.553 & Taisho-5 & 0.02 & National-3 & -0.934 \\
\hline Standard(p)-1 & 1.717 & Globe-3 & 0.53 & Drill-2 & -0.105 & National-4 & -0.934 \\
\hline Taisho-1 & 1.558 & Standard(t)-3 & 0.448 & Globe-2 & -0.105 & Jack\&Betty-2 & -1.015 \\
\hline Jack\&Betty-1 & 1.413 & Globe-4 & 0.44 & Jack\&Betty-3 & -0.203 & Union-3 & -1.104 \\
\hline Standard(p)-5 & 1.391 & Globe-1 & 0.435 & Taisho-4 & -0.302 & Choice-2 & -1.176 \\
\hline Drill-1 & 1.294 & Dening-2 & 0.431 & Drill-4 & -0.316 & Union-2 & -1.33 \\
\hline Standard(p)-4 & 1.197 & Standard(p)-2 & 0.416 & Standard(t)-1 & -0.323 & Union-1 & -1.46 \\
\hline Union-5 & 1.177 & Drill-5 & 0.377 & Standard(t)-2 & -0.351 & National-2 & -1.638 \\
\hline Standard(t)-5 & 0.946 & Choice-5 & 0.361 & Jack\&Betty-4 & -0.391 & Choice-1 & -2.568 \\
\hline Standard(t)-4 & 0.835 & Dening-3 & 0.306 & Choice-3 & -0.41 & National-1 & -2.793 \\
\hline Dening-5 & 0.696 & Jack\&Betty-5 & 0.193 & Pacific-2 & -0.46 & & \\
\hline Globe-5 & 0.666 & Pacific-5 & 0.139 & Pacific-3 & -0.57 & & \\
\hline Standard(p)-3 & 0.664 & Dening-1 & 0.116 & Taisho-2 & -0.642 & & \\
\hline Dening-4 & 0.599 & Choice-4 & 0.085 & Drill-3 & -0.649 & & \\
\hline Union-4 & 0.584 & Pacific-4 & 0.042 & Taisho-3 & -0.702 & & \\
\hline
\end{tabular}


On Dim 2, as it is clear in Table 6, the value was the highest for Pacific-1 (1.885) and the second highest for Standard $(p)-1$ (1.717) , while it is the lowest for National1 (-2.793) and the second lowest for Choice-1 (-2.568), Taisho-5 being around the zero point. In decreasing order, the fifty-five textbooks were: Pacific-1 > Standard $(p)-1>$ Taisho-1 $>$ JackEBetty-1 $>$ Standard $(p)-5>$ Drill-1 $>\operatorname{Standard}(p)-4>$ Union-5 $>$ Standard $(t)-5>$ Standard $(t)-4>\ldots . .>$ National $-3>$ National $-4>$ JackEBetty $2>$ Union-3 > Choice-2 > Union-2 > Union-1 > National-2 > Choice-1 > National-1.

The differences of the fifty-five textbooks on Dim 2 could best be explained by the category of artificial-sounding (+) vs.natural-sounding (-) discourse. As it is clear in the following examples, in Pacific-1 (the highest) and Standard(p)-1 (the second highest), and the other high-scoring ones, the texts tended to sound more artificial in the sense that they observe the 'pattern drill first' principle, while National-1 and the other low-scoring ones observe the 'free communication first' principle as a basic strategy for the textbook organization, seldom using narrative styles or dialogues in or related to the core pieces.

Mention must be made concerning the definition of 'artificial-/natural-sounding' on Dim 2. In the higher-scoring Book 4 or Book 5 textbooks such as Standard(p)5 (the fifth highest), Standard(p)-4 (seventh highest) Union-5 (the eighth highest), Standard(t)-5 (the ninth highest), Standard(t)-4 (the tenth highest), the artificialsounding should be interpreted as "exposition-oriented texts" meaning few narratives with direct speech quotations inserted and/or the passages followed or preceded by the dialogues connected to the core piece, while its antonym, natural-sounding as "speech-oriented" meaning more narratives used with direct speech quotations inserted and/or the passages followed or preceded by the related dialogues (Honda et al., 2019).

Table 7 shows the values of the fifty-five textbooks on Dim 3. On Dim 3, the value was the highest for Choice-1 (2.059), the second highest for National-1 (2.032), while it is the lowest for Drill-1 (-3.835) and the second lowest for JackEBetty-2 (-2.006). In decreasing order, the fifty-five textbooks were: Choice-1 > National-1 > Standard $(p)-1>$ Globe-1 $>$ Union-5 $>$ Taisho-1 $>$ Standard $(p)-5>$ Standard $(p)-4>$ Globe$5>$ Globe-4 $>\ldots . .>$ JackEBetty-4 $>$ Dening-3 $>$ Drill-3 $>$ Union-3 $>$ Drill-2 $>$ Globe-2 $>$ JackEBetty-1 > JackEBetty-3 > JackEBetty-2 > Drill-1.

Table 7: Values on Dim 3

\begin{tabular}{|l|r|l|r|l|r|l|r|}
\hline & Dim 3 & & Dim 3 & & \multicolumn{1}{c|}{ Dim 3 } & & \multicolumn{1}{c|}{ Dim 3} \\
\hline Choice-1 & 2.059 & Standard(t)-3 & 0.463 & Dening-5 & -0.101 & Jack\&Betty-4 & -0.642 \\
\hline National-1 & 2.032 & Standard(t)-4 & 0.409 & Drill-5 & -0.166 & Dening-3 & -0.69 \\
\hline Standard(p)-1 & 1.895 & Union-4 & 0.393 & Dening-4 & -0.201 & Drill-3 & -0.691 \\
\hline Globe-1 & 1.882 & Standard(p)-3 & 0.336 & Choice-2 & -0.306 & Union-3 & -0.72 \\
\hline Union-5 & 1.365 & Union-1 & 0.242 & National-2 & -0.321 & Drill-2 & -1.061 \\
\hline Taisho-1 & 1.291 & Pacific-1 & 0.24 & Dening-2 & -0.402 & Globe-2 & -1.061 \\
\hline Standard(p)-5 & 0.877 & Pacific-2 & 0.201 & Choice-3 & -0.428 & Jack\&Betty-1 & -1.062 \\
\hline Standard(p)-4 & 0.869 & Choice-5 & 0.117 & Jack\&Betty-5 & -0.443 & Jack\&Betty-3 & -1.162 \\
\hline Globe-5 & 0.775 & Taisho-2 & 0.086 & Taisho-3 & -0.466 & Jack\&Betty-2 & -2.006 \\
\hline Globe-4 & 0.718 & Taisho-5 & 0.069 & Dening-1 & -0.487 & Drill-1 & -3.835 \\
\hline Standard(t)-1 & 0.707 & Standard(p)-2 & 0.048 & Union-2 & -0.489 & & \\
\hline Standard(t)-5 & 0.653 & Pacific-5 & -0.033 & National-3 & -0.499 & & \\
\hline Pacific-4 & 0.545 & Standard(t)-2 & -0.036 & National-4 & -0.499 & & \\
\hline Globe-3 & 0.538 & Choice-4 & -0.059 & Drill-4 & -0.525 & & \\
\hline National-5 & 0.503 & Taisho-4 & -0.092 & Pacific-3 & -0.634 & & \\
\hline
\end{tabular}


The differences of these fifty-five textbooks on Dim 3 could best be explained by the category of dialogue-based (+) vs. passage-based (-) textbooks. As it is clear in the following examples, Choice-1 (the highest), National-1 (the second highest), Standard ( $p$ )-1 (the third highest) and the other high-scoring ones favor dialogues more frequently throughout their lessons. On the contrary, Drill-1 (the lowest), JackEBetty-2 (the second lowest), Jack\&Betty-3 (the third lowest) and the other lowscoring ones favor expository passages more frequently throughout their texts, without exceptions. For example, Choice-1 and National-1, the two most highscoring ones, prefer and adopt dialogue-based discourses, while Drill-1 and JackEBetty-2, the two most low-scoring ones, prefer and adopt passage-based discourses. The extract from Drill-1 below does look like a dialogue between Teacher and Pupil, but closely examined, it is essentially a Teacher's 'teacher talk,' in which Teacher controls hundred per cent of the discourse. For this reason it could and should be categorized as a kind of expository passage, not a conversation in the true sense of the word.

It is interesting to note that dialogue-based, higher-year textbooks such as Union5 (the fifth highest), Standard-(p)-5 (the seventh highest) and others are rich in variety in the sense that in their lessons the main bodies (core expository passages) are usually preceded by the introductory questions, dialogues, or hints and/or followed by the post-reading comments, proverbs, related poems or dialogues on the passages (Honda et al., 2019). For example, in Union-5, the first unit consists of main bodies (two expository passages), i.e., "Achievements and Dignity of Labor" and "Power of the Hand," and they are followed by the two poems related to the contents of the main expository passages, i.e., "There's Work Enough to Do" and "Fields for Labor." This variety in style or linguistic activity seems to be intended to help the learners understand and discuss the contents of the topics dealt with in the core pieces. On the contrary, lower-year textbooks generally value expository passages, only carrying them, nothing else (Honda et al, 2019).

It has to be noted in this respect that the feature of Dim 3, dialogue-based (+) vs. passage-based (-) textbooks has to be interpreted from a broader perspective including the category of "variety-rich vs. variety-poor." The contribution rate of the third dimension was 0.06 , covering only the $6 \%$ of the whole contribution.

Table 8: Values on Dim 4

\begin{tabular}{|l|r|l|r|l|r|l|r|}
\hline & Dim 4 & & Dim 4 & & Dim 4 & & Dim 4 \\
\hline Choice-1 & 2.584 & Dening-3 & 0.47 & Drill-4 & 0.009 & Pacific-1 & -0.992 \\
\hline National-1 & 2.326 & Standard(t)-4 & 0.458 & Drill-3 & -0.087 & Choice-2 & -1.061 \\
\hline Drill-1 & 2.258 & Standard(p)-3 & 0.455 & Globe-3 & -0.121 & National-3 & -1.071 \\
\hline Union-5 & 1.033 & Dening-2 & 0.45 & Taisho-5 & -0.128 & National-4 & -1.071 \\
\hline Union-1 & 0.992 & Globe-5 & 0.449 & Standard(t)-2 & -0.152 & Taisho-4 & -1.099 \\
\hline Jack\&Betty-1 & 0.828 & Drill-2 & 0.385 & Jack\&Betty-2 & -0.153 & Union-3 & -1.15 \\
\hline Dening-5 & 0.781 & Globe-2 & 0.385 & Taisho-2 & -0.201 & Taisho-3 & -1.231 \\
\hline Standard(t)-5 & 0.735 & Standard(t)-3 & 0.35 & Choice-3 & -0.231 & Taisho-1 & -1.278 \\
\hline Dening-4 & 0.7 & Dening-1 & 0.213 & Standard(t)-1 & -0.469 & Pacific-2 & -1.633 \\
\hline Standard(p)-5 & 0.7 & Choice-4 & 0.191 & Jack\&Betty-3 & -0.526 & Globe-1 & -3.067 \\
\hline Union-4 & 0.687 & Standard(p)-1 & 0.184 & Pacific-5 & -0.783 & & \\
\hline Standard(p)-4 & 0.683 & Globe-4 & 0.098 & Pacific-4 & -0.788 & & \\
\hline Drill-5 & 0.565 & Standard(p)-2 & 0.072 & National-2 & -0.902 & & \\
\hline National-5 & 0.535 & Jack\&Betty-5 & 0.065 & Union-2 & -0.931 & & \\
\hline Choice-5 & 0.505 & Jack\&Betty-4 & 0.022 & Pacific-3 & -0.977 & & \\
\hline
\end{tabular}


On Dim 4, as it is clear in Table 8, the value is the highest for Choice-1 (2.584), the second highest for National-1 (2.326) and the third highest for Drill-1 (2.258), while it is the lowest for Globe-1 (-3.067), the second lowest for Pacific-2 (-1.633) and the third lowest for Taisho-1 (-1.278), the other textbooks being between them. In decreasing order, the thirteen textbooks were: Choice-1 $>$ National-1 $>$ Drill-1 $>$ Union-5 > Union-1 > JackEBetty-1 > Dening-5 > Standard(t)-5 > Dening-4 > Standard $(p)-5>\ldots . .>$ Pacific-1 $>$ Choice-2 $>$ National-3 $>$ National-4 $>$ Taisho-4 $>$ Union-3 > Taisho-3 > Taisho-1 > Pacific-2 > Globe-1.

The differences of these fifty-five textbooks on Dim 4 could best be explained by the category of teacher-dominance (+) vs. non-teacher-dominance (-). As it is clear in the following examples cited from Choice-1 (the highest), not a few texts are comprised of dialogs in which a teacher (superior) dominates pupils (inferiors) in the linguistic activity, while in Globe-1 (the lowest) and other low-scoring textbooks there were few such features observed in the texts. For this reason, the Dim 4 was termed teacher-dominance vs. non-teacher-dominance, just as in the Book1 and Book-3 results (Honda et al., 2018, Asai et al., 2019). The contribution rate of Dim 4 was 0.05 , covering only the $5 \%$ of the whole contribution.

It has to be noted in this respect that in the Book- 5 interpretation, Dim 4 was termed teacher-assistance vs. non-teacher-assistance, which was closely related to but slightly different from the names of Dim 4 in the Book-1 and Book-3 interpretations, i.e., teacher-dominance $(+)$ vs. non teacher-dominance (Honda et al., 2018; Asai et al., 2019). For this reason, the feature of Dim 4, dominance (+) vs. nonteacher-dominance (-) should be interpreted from a broader perspective including the category of teacher-assistance vs. non-teacher-assistance.

Table 9: Values on Dim 5

\begin{tabular}{|l|r|l|r|l|r|l|r|}
\hline & \multicolumn{1}{|c|}{ Dim 5 } & & \multicolumn{1}{c|}{ Dim 5 } & & \multicolumn{1}{c|}{ Dim 5 } & Dim 5 \\
\hline Drill-1 & 3.482 & Jack\&Betty-3 & 0.34 & Choice-3 & 0.064 & Choice-1 & -0.383 \\
\hline Taisho-1 & 1.446 & Standard(t)-5 & 0.335 & Jack\&Betty-2 & 0.017 & Union-2 & -0.384 \\
\hline Globe-1 & 1.305 & Globe-3 & 0.3 & National-1 & -0.01 & Union-3 & -0.734 \\
\hline Pacific-3 & 1.126 & Union-1 & 0.297 & Choice-4 & -0.045 & Dening-4 & -0.94 \\
\hline Pacific-2 & 0.946 & Jack\&Betty-5 & 0.249 & Choice-2 & -0.067 & Dening-5 & -1.054 \\
\hline Standard(p)-1 & 0.859 & Union-4 & 0.212 & Taisho-2 & -0.074 & Dening-2 & -1.214 \\
\hline Standard(p)-4 & 0.7 & Globe-5 & 0.211 & Standard(t)-2 & -0.105 & Dening-1 & -1.23 \\
\hline Pacific-4 & 0.62 & Standard(t)-1 & 0.189 & Standard(t)-3 & -0.136 & Dening-3 & -1.464 \\
\hline Union-5 & 0.612 & Choice-5 & 0.178 & Taisho-3 & -0.182 & Pacific-1 & -3.193 \\
\hline Standard(p)-3 & 0.558 & Standard(p)-2 & 0.145 & Drill-2 & -0.215 & Jack\&Betty-1 & -3.201 \\
\hline Globe-4 & 0.524 & National-3 & 0.095 & Globe-2 & -0.215 & & \\
\hline National-5 & 0.523 & National-4 & 0.095 & Taisho-5 & -0.265 & & \\
\hline Standard(p)-5 & 0.439 & Taisho-4 & 0.091 & Drill-3 & -0.269 & & \\
\hline Jack\&Betty-4 & 0.401 & National-2 & 0.081 & Pacific-5 & -0.312 & & \\
\hline Standard(t)-4 & 0.383 & Drill-5 & 0.079 & Drill-4 & -0.367 & & \\
\hline
\end{tabular}

On Dim 5, as it is clear in Table 9, the value is the highest for Drill-1 (3.482), the second highest for Taisho-1 (1.446), and the lowest for Jack\&Retty-1 (-3.201) and the second lowest for Pacific-1 (-3.193), the others coming in between them. In decreasing order, the fifty-five textbooks were: Drill-1 $>$ Taisho-1 $>$ Globe-1 $>$ Pacific-3 > Pacific-2 > Standard(p)-1 > Standard(p)-4 > Pacific-4 > Union-5 > 
Standard $(p)-3>\ldots . .>$ Choice-1 $>$ Union-2 $>$ Union-3 $>$ Dening- $4>$ Dening-5 $>$ Dening$2>$ Dening-1 $>$ Dening-3 $>$ Pacific-1 $>$ JackEBetty-1.

The difference of the fifty-five textbooks on Dim 5 could best be explained by the category of strictly-controlled (+) vs. loosely-controlled (-) texts. In Drill-1 (the highest), Taisho-1 (the second highest), Globe-1 (the third highest) and the other high-scoring ones, linguistic items were strictly selected or controlled from the teaches' (superiors') viewpoint, while in Jack\&Betty-1 (the lowest), Pacific-1 (the second lowest), Dening-3 (the third lowest) and the other low-scoring ones, this kind of linguistic control was not generally observed, with more freedom given for natural communicative activity. In other words, Drill-1 and the others observe the principle of grammar and vocabulary control as a basic strategy for EFL textbook organization, while Jack\&Betty-1 and the others value the principle of natural communicative activity. For this reason, Dim 5 was termed strictlycontrolled vs. loosely-controlled texts, just as in the Book-1 results (Honda et al., 2018) and the Book-3 results (Asai et al., 2019). Thus, in the present CA, the name, feature and axis of Dim 5 were basically the same as those of the results of the Book-1 and Book-3 CAs. The contribution rate of Dim 5 was 0.041 , covering only $4.1 \%$ of the whole contribution.

Table 10: Values on Dim 6

\begin{tabular}{|l|r|l|r|l|r|l|r|}
\hline & Dim 6 & & Dim 6 & & \multicolumn{1}{l|}{ Dim 6 } & & Dim 6 \\
\hline Taisho-1 & 2.116 & Drill-1 & 0.573 & Standard(p)-1 & -0.122 & Drill-3 & -0.574 \\
\hline Union-1 & 1.777 & Taisho-2 & 0.475 & Standard(p)-4 & -0.124 & Globe-4 & -0.584 \\
\hline Pacific-1 & 1.692 & Pacific-5 & 0.44 & Choice-1 & -0.134 & Dening-2 & -0.672 \\
\hline Union-2 & 1.686 & Jack\&Betty-5 & 0.284 & Standard(t)-4 & -0.147 & Standard(p)-2 & -0.766 \\
\hline Pacific-2 & 0.958 & National-2 & 0.21 & Dening-5 & -0.158 & Dening-1 & -0.77 \\
\hline Union-4 & 0.953 & Choice-3 & 0.109 & Drill-5 & -0.216 & Dening-3 & -0.925 \\
\hline Taisho-3 & 0.933 & Choice-2 & 0.1 & Pacific-3 & -0.262 & Drill-2 & -1.666 \\
\hline Union-5 & 0.923 & Jack\&Betty-3 & 0.083 & Standard(t)-3 & -0.262 & Globe-2 & -1.666 \\
\hline National-3 & 0.882 & Globe-5 & 0.057 & Standard(p)-3 & -0.326 & Jack\&Betty-2 & -1.836 \\
\hline National-4 & 0.882 & Standard(p)-5 & 0.018 & Jack\&Betty-4 & -0.351 & Globe-1 & -4.102 \\
\hline Taisho-5 & 0.843 & Choice-5 & -0.02 & National-1 & -0.433 & & \\
\hline Union-3 & 0.818 & Standard(t)-5 & -0.026 & Dening-4 & -0.494 & & \\
\hline National-5 & 0.692 & Choice-4 & -0.046 & Jack\&Betty-1 & -0.496 & & \\
\hline Pacific-4 & 0.666 & Globe-3 & -0.057 & Standard(t)-1 & -0.507 & & \\
\hline Taisho-4 & 0.601 & Standard(t)-2 & -0.087 & Drill-4 & -0.57 & & \\
\hline
\end{tabular}

On Dim 6, as it is clear in Table 10, the value is the highest for Taisho-1 (2.116), the second highest for Union-1 (1.777), the third highest for Pacific-1 (1.692), and the lowest for Globe-1 (-4.102) and the second lowest for JackEBetty-2 (-1.836), the others coming in between them. In decreasing order, the fifty-five textbooks were: Taisho-1 > Union-1 > Pacific-1 > Union-2 > Pacific-2 > Union-4 > Taisho-3 > Union-5 $>$ National-3 $>$ National $-4>\ldots . .>$ Drill-3 $>$ Globe-4 $>$ Dening-2 $>$ Standard $(p)-2>$ Dening-1 > Dening-3 > Drill-2 > Globe-2 > JackEBetty-2 > Globe-1.

The difference of the fifty-five textbooks on Dim 6 could best be explained by the category of redundant (+) vs. concise (-) texts; in Taisho-1 (the highest) and other high-scoring ones, a considerably large parts of the texts tend to be long and 
redundant in the sense that the dialogues and expository passages are interwoven with other related drill-based repetitive activities such as grammar, structure, Japanese into English translation, spelling, etc. or some of the discourses are longer and somewhat desultory, while in Globe-1 (the lowest) and other lowscoring textbooks the passages and dialogues were generally brief and concise without tedious drill-like activities.

For this reason, Dim 6 was termed redundant vs. concise texts, just as in the Book-1 and Book-3 results (Honda et al., 2018; Asai et al., 2019). It has to be noted in this respect that the name, feature and axis of Dim 6 were basically the same as the results of the Book-1 CA and of the Book-3 CA except for the location of the plusminus poles in the present CA and the Book-1 CA. The contribution rate of Dim 6 was 0.036 , covering only $3.6 \%$ of the whole contribution.

Table 11: Values on Dim 7

\begin{tabular}{|l|r|l|r|l|r|l|r|}
\hline & \multicolumn{1}{|c|}{ Dim 7} & & \multicolumn{1}{|c|}{ Dim 7} & & \multicolumn{1}{c|}{ Dim 7} & & Dim 7 \\
\hline Pacific-3 & 1.999 & Standard(p)-4 & 0.637 & Choice-2 & -0.063 & Dening-4 & -1.066 \\
\hline Pacific-2 & 1.886 & Standard(p)-5 & 0.481 & Standard(t)-5 & -0.101 & Dening-1 & -1.094 \\
\hline Jack\&Betty-2 & 1.826 & Standard(p)-1 & 0.419 & National-1 & -0.2 & Union-3 & -1.207 \\
\hline Pacific-4 & 1.683 & Union-4 & 0.386 & Drill-3 & -0.222 & Dening-2 & -1.274 \\
\hline Jack\&Betty-1 & 1.55 & Globe-3 & 0.358 & Choice-4 & -0.281 & Union-2 & -1.328 \\
\hline Jack\&Betty-4 & 1.187 & Standard(t)-1 & 0.33 & Drill-5 & -0.306 & Dening-5 & -1.425 \\
\hline Globe-4 & 1.137 & National-3 & 0.305 & Drill-4 & -0.387 & Drill-1 & -1.645 \\
\hline Union-5 & 1.105 & National-4 & 0.305 & Choice-1 & -0.476 & Taisho-1 & -1.762 \\
\hline Drill-2 & 0.97 & Choice-5 & 0.3 & Taisho-3 & -0.484 & Dening-3 & -1.783 \\
\hline Globe-2 & 0.97 & National-2 & 0.29 & Jack\&Betty-5 & -0.596 & Globe-1 & -2.191 \\
\hline National-5 & 0.932 & Standard(t)-2 & 0.254 & Pacific-5 & -0.635 & & \\
\hline Jack\&Betty-3 & 0.847 & Pacific-1 & 0.2 & Choice-3 & -0.77 & & \\
\hline Globe-5 & 0.822 & Standard(p)-3 & 0.182 & Taisho-5 & -0.817 & & \\
\hline Standard(t)-3 & 0.733 & Taisho-4 & 0.115 & Union-1 & -0.925 & & \\
\hline Taisho-2 & 0.674 & Standard(t)-4 & 0.099 & Standard(p)-2 & -0.982 & & \\
\hline
\end{tabular}

On Dim 7, as it is clear in Table 11, the value is the highest for Pacific-3 (1.999), the second highest for Pacific-2 (1.886), the third highest for JackEBetty-2 (1.826), and the lowest for Globe-1 (-2.191), the second lowest for Dening-3 (-1.783), the third lowest for Taisho-1 (-1.762) and the others coming in between them. In decreasing order, the fifty-five textbooks were: Pacific-3 > Pacific-2 > JackEBetty-2 > Pacific-4 $>$ JackEBetty-1 > JackEBetty-4 $>$ Globe-4 $>$ Union-5 $>$ Drill-2 $>$ Globe- $>$. ... > Dening$4>$ Dening-1 $>$ Union-3 > Dening-2 > Union-2 > Dening-5 > Drill-1 > Taisho-1 > Dening-3 $>$ Globe-1.

The difference of the fifty-five textbooks on Dim 7 could best be explained by the category of connected (+) vs. disconnected (-) contents. In Pacific-3 (the highest), Pacific-2 (the second highest), JackEBetty-2(the third highest) and the other highscoring ones, the contents of the passages in the lessons are semantically and contextually connected; especially in Pacific-3(the highest), Pacific-2(the second highest), JackEBetty-2(the third highest) and the others, their main characters and their families consistently appear throughout the volume, while in Dening-3 (the second lowest), Taisho-1 (the third highest) and the other low-scoring ones, except 
for Globe-1 (the lowest), the contents are not connected in any way. (It has to be noted that Globe-1 (the lowest) has to be treated as an exception since its contents are semantically and contextually connected throughout the volume.) For this reason, the Dim 7 was termed connected vs. disconnected contents, just as in the Book-1 CA (Honda et al., 2018) and the Book-3 CA solutions (Asai et al., 2019). The contribution rate of Dim 7 was 0.029 , covering only $2.9 \%$ of the whole contribution.

It has to be admitted that the naming and characterization of the Dims in the present CA turned to be a difficult job as it had been expected. This was because the present CA had to analyze an extremely large corpus comprised of fifty-five textbooks in total, covering five years ( $1^{\text {st }}$ to $5^{\text {th }}$ year) and eleven kinds. This might have been the main reason that made the dimension-naming difficult.

The bipolar CA map in Figure 1 visualizes the $58.9 \%$ of the spatial interrelationships identified among the fifty-five categorical variants in focus, in which the $x$-axis (horizontal axis) represents Dim 1 (difficult (+) vs. easy (-) texts) and the $y$-axis (vertical axis) Dim 2 (artificial-sounding (+) vs. natural-sounding (-) discourse). Because these Dims are the two most predominant ones among the seven Dims identified, covering almost $60 \%$ of the whole contribution rates, they can be regarded as the major Dims representing the present major CA results.

This bipolar visualization seems to reveal several interesting facts concerning the features of each of the fifty-five textbooks and their mutual inter-relationships. First, there were a large number of textbooks clustered around the area characterized by 'neutral texts (around zero point)' on the difficult/easy axis (the $x$ axis) and 'natural-sounding texts (minus-pole) on the naturalness/artificialness axis (the $y$-axis).' This cluster, termed 'natural-sounding cluster' or 'Cluster A,' was comprised of the following twenty-two textbooks, mostly second- and third-year textbooks.

Drill-2, Globe-2, JackEBetty-3, Taisho-4, Drill-4, Standard(t)-1, Standard(t)-2, JackEBetty-4, Choice-3, Pacific-2, Pacific-3, Taisho-2, Drill-3, Taisho-3, National-3, National-4, JackEBetty-2, Union-3, Choice-2, Union-2, Union-1, National-2

The texts of these textbooks were judged to be neutral in readability or difficulty and natural-sounding daily-life-based dialogues rather than artificially polished expository passages. This judgment could also be supported by the fact that they were mostly textbooks written for the lower-level students such as the secondyear or third-year students. 


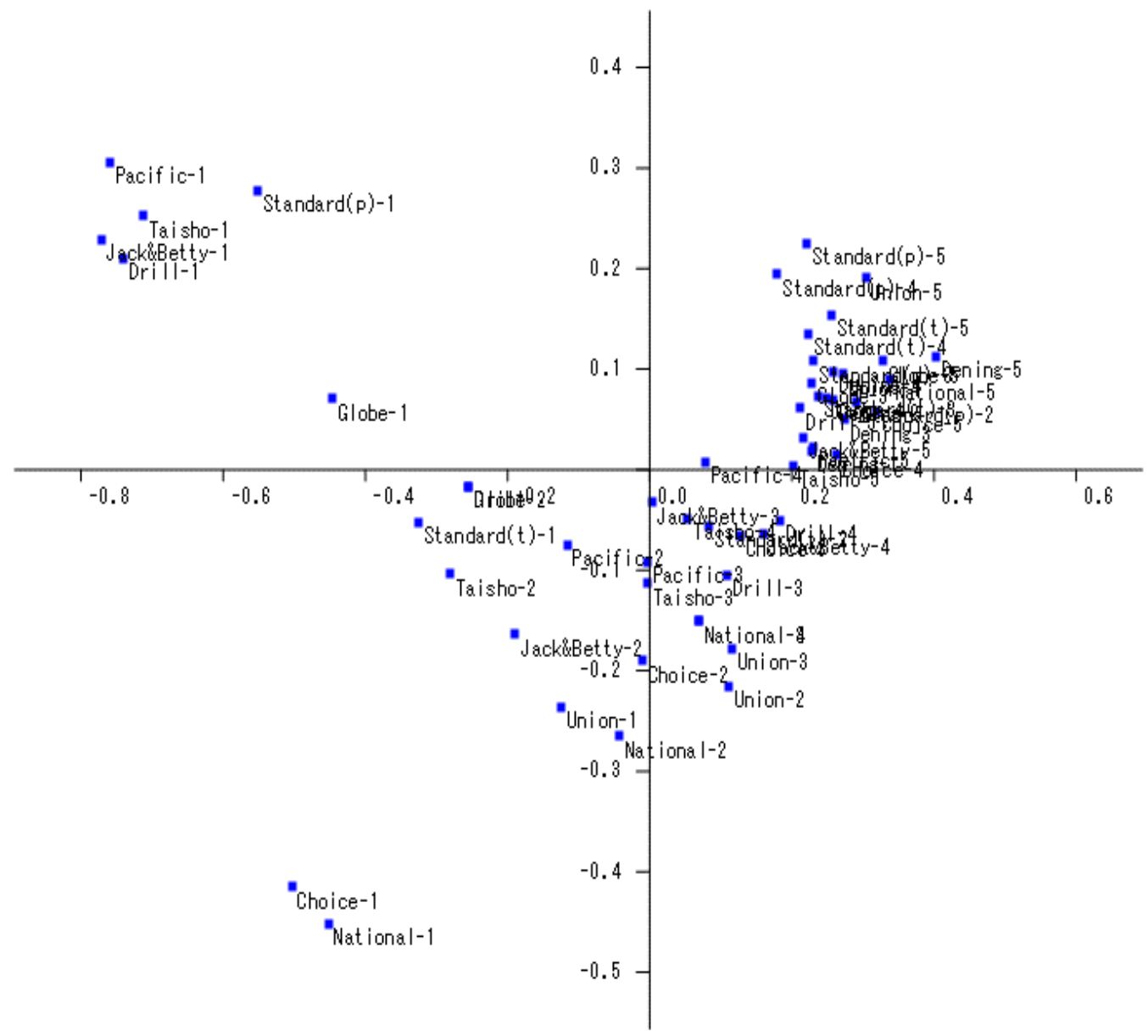

X-axis (Dim 1): difficult (+) vs. easy (-) texts (46.9\%)

Y-axis (Dim 2): artificial-sounding (+) vs. natural-sounding discourse (-) (12.0\%)

Figure 1: CA Map of 55 Textbooks

Second, there were also a large number of textbooks clustered around the area characterized by difficult texts (plus on the $x$-axis) and artificial-sounding texts (plus on the $y$-axis). This cluster, termed 'difficult and artificial-sounding' or 'Cluster B,' was comprised of the following twenty-four textbooks, mostly fourth- and fifthyear textbooks.

Dening-5, National-5, Globe-5, Choice-5, Union-5, Standard(p)-2, Dening-3, Union-4, Choice-4, Dening-4, Dening-2, Standard(t)-5, Globe-4, Standard(t)-3, Standard(p)-3, Pacific-5, Globe-3, Dening-1, Standard(t)-4, Standard(p)-5, JackEBetty-5, Drill-5, Taisho-5, Pacific-4

The texts of these textbooks were judged to be both difficult and artificial in the sense that they are artificially polished expository passages rather than naturalsounding daily-life-like dialogues. This judgment could also be supported by the fact that they are mostly textbooks written for the fifth-year or fourth-year 
students and/or authored by native-speaker authors, such as Dening (Dening), Sanders (Union), Barnes (National) and Palmer (Standard(p)).

Third, there were a rather small number of textbooks clustered around the area characterized by easy in readability (located around the minus area of the $x$ (difficult/easy)-pole). This cluster, termed 'easy' or 'Cluster C,' was comprised of the following eight textbooks, all of them being first-year textbooks.

Pacific-1, Standard(p)-1, Taisho-1, JackEBetty-1, Drill-1, Globe-1, Choice-1 National-1

These easy textbooks could further be divided into two classes, (1) easy and artificial-sounding ones (Cluster C-1) and (2) easy and natural-sounding ones (Cluster C-2), depending upon their locations on the $y$-pole or the artificial-/ natural-sounding pole. As it is clear in Figure 1, the Cluster C-1 textbooks, i.e., Pacific-1, Standard(p)-1, Taisho-1, JackEBetty-1, Drill-1 and Globe-1, could be characterized as the textbooks which valued repetitive, drill-based language activities more than natural communication. On the contrary, the Cluster C-2 textbooks, Choice-1 and National-1 could be characterized as the textbooks which valued natural-sounding expressions more than artificial, repetitive, drill-based activities.

An interesting fact to be noted in this respect is that National-1, a textbook authored by a U.S. author for U. S. primary school grade-1 learners, published in U.S. A., and imported to Japan to be used in Japanese middle schools, was at the same level in readability as the textbooks authored by Japanese authors for Japanese middle school first-year learners. Probably this might be one of the reasons that National-1 was popular among Japanese EFL teachers and learners in the pre-war days in Japan.

Clearly, it was both Dim 1, i.e., $x$-axis, named 'difficult vs. easy texts' and Dim 2, i.e., $y$-axis, named 'artificial-sounding vs. natural-sounding discourse' that differentiated this large number of textbooks from among each other. This will prove that both of the two axes, both the $x$-axis and the $y$-axis, are equally efficient and powerful differentiators of these EFL textbooks in focus. 


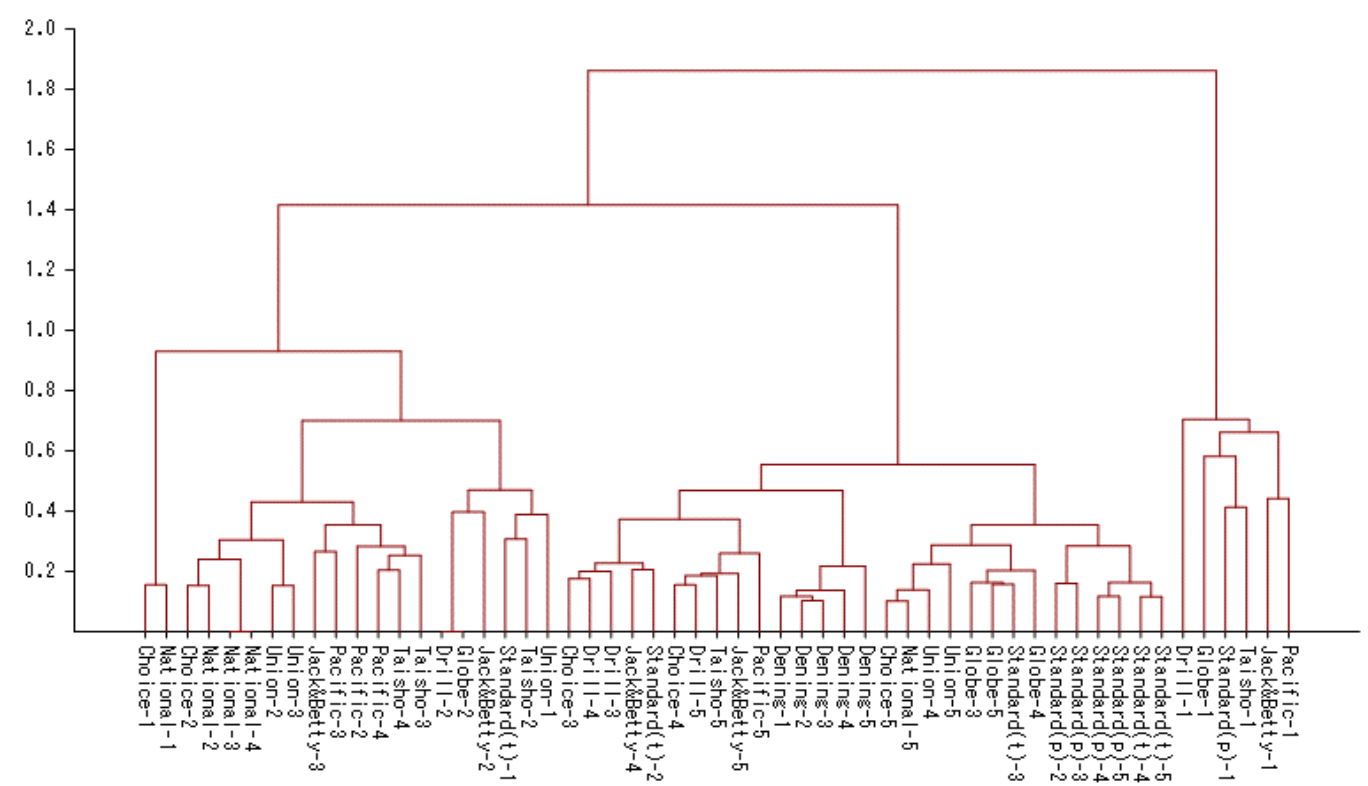

Figure 2: Dendrogram by Ward Method (100\%)

It is true that the bipolar map based on the two selected major axes can display the major features of the fifty-five textbooks graphically but naturally it cannot depict all of their features detected in the present CA. As the cumulative contribution rates show in Table 3, the bipolar map comprised of the two axes can only display $58.9 \%$ of the whole features, leaving the rest $(41.1 \%)$ untouched. To solve this problem, an attempt was made to display the whole features of their differences, using cluster analysis (Ward method) and dendrogram (Figure 2). (For further explanation of dendrogram see Asai et al., 2019, p. 42.)

Figure 2 graphically describes the differences of the fifty-five textbooks based on the values of the fifty-four Dims identified. As it is shown in Figure 2, there were three groups formed in the dendrogram, Group A, B and C. Group A, which corresponds to Cluster A above, was comprised of the following twenty textbooks.

Choice-1, National-1, Choice-2, Nationa-2, National-3, Nationa-4, Union-2, Union-3, JackEBetty-3, Pacific-3, Pacific-2, Pacific-4, Taisho-4, Taisho-3, Drill2, Globe-2, Jack\&Betty-2, Standard(t)-1, Taisho-2, Union-1

Among these twenty textbooks, seventeen ones were identical with those from among Cluster A above, which suggests that the two Dims, i.e., difficulty/easiness (Dim 1) and artificial-/natural-sounding (Dim 2), were the most influential on their categorization and classification.

Group B, which corresponds to Cluster B above, was comprised of the twentynine textbooks.

Choice-3, Drill-4, Drill-3, JackEBetty-4, Standard(t)-2, Choice-4, Drill-5, Taisho-5, Jack\&Betty-5, Pacific-5, Dening-1, Dening-2, Dening-3, Dening-4, Dening-5, Choice-5, National-5, Union-4, Union-5, Globe-3, Globe-5, 
Standard(t)-3, Globe-4, Standard(p)-2, Standard(p)-3， Standard(p)-4, Standard( $p)-5$, Standard(t)-4, Standard(t)-5

Among these twenty-nine textbooks, twenty-three ones were identical with those from among Cluster B above, which also suggests that the two Dims, i.e., difficulty/easiness (Dim 1) and artificial-/natural-sounding (Dim 2), were the most influential on their categorization and classification.

Group C, which corresponds to Cluster C above, more specifically, Custer C-1, was comprised of the following six textbooks, all of them being first-year textbooks.

\section{Drill-1, Globe-1, Standard(p)-1, Taisho-1, JackEBetty-1, Pacific-1}

All of these six textbooks were identical with those from among Cluster $\mathrm{C}$ above , which also suggests that the two axes, i.e., difficulty/easiness (Dim 1) and artificial/natural-sounding (Dim 2), were the most influential on their categorization and classification.

It has to be noted that all of these Dendrogram-classifications were based on the judgment of the fifty-four Dims identified (the seven named Dims and the fortyseven unnamed ones). Also, Group A and Group B were combined together to form a larger Group $A B$, and further, Group $A B$ and Group $C$ were further combined to form a larger group, Group ABC.

\section{Conclusion, recommendations, limitations and future research}

It was proved in the present study that CA can handle quite a large amount of textual corpus, discriminating such a large number of EFL textbooks and clarifying the viewpoints necessary for this work. This means that CA is a useful statistic tool for the textual analyses in the language -related areas.

As for the recommendations to be derived from the present study results, the following are to be pointed out.

- In analyzing and evaluating English (EFL) textbooks, practitioners can make good use of the seven viewpoints, i.e., (1) difficult / easy texts, (2) artificial- / natural-sounding discourse, (3) dialogue-/ passage-based textbooks, (4) teacher- / non teacher-dominance, (5) strictly / loosely controlled, (6) redundant/concise and (7) connected/disconnected.

- Among them, practitioners can focus on (1) difficult / easy texts since it is the most powerful factor that discriminates the features of English (EFL) textbooks.

- If it is necessary to grasp the fairly comprehensive picture of English (EFL) textbooks, practitioners can focus on the two viewpoints, the most powerful and the second most powerful viewpoints, i.e., (1) difficult / easy texts and (2) artificial-/ natural-sounding discourse.

If teachers can analyze or evaluate the textbooks used in the classroom from such viewpoints, they will be able to help their learners' learning and evaluate it from the light of qualitative aspect of the textbooks.

Concerning limitations of the present $\mathrm{CA}$, the following points are to be made. 
First, as stated earlier, although the differences of the Books-1-5 textbooks were explained by the same Dims as those of the Book- 1 and Book -3 results up to Dim 7, there were two exceptions noted in the analysis (Honda et al. (2019). The Dim 3 of the Book-5 CA was termed variety-rich vs. variety-poor, which was different from those of the Book-1, Book-3 (Honda et al. (2019) and the present CA. Also, The Dim 4 of the Book-5 CA was termed teacher-assistance vs. non teacher-assistance, while those of Book-1, Book-3 and the present CA were teacher dominance vs. non teacher dominance (Honda et al. (2019). It has to be admitted that although the results of the four CAs were almost the same on the whole, there were some inconsistencies or irregularities observed on minor points. These facts suggest the limitations of the present CA and a need of further make-up study, specifically a need of qualitative studies of these EFL textbooks.

Second, the present CA results have nothing to say on the relationship (homogeneities / differences) of the fifty-five historical EFL textbooks to the currently used ones, since there were no current EFL textbooks included as categorical variants in the present CA, due to a lack of capacity for the analysis. It has to be admitted that this is a serious weakness of the present research model. To solve this problem, there must be chances to conduct a new CA, using both historical and current EFL textbooks as categorical variants, in order to probe into their mutual relationships.

Finally, it must be admitted and emphasized that the results of these quantitative analyses including the present CA could and should be double-checked by the qualitative analyses of the same samples used. The qualitative confirmation of the validity of a quantitative analysis (or vice versa) is essential in academic pursuit. This should be the main theme in the next study.

\section{References}

Asai, T., Honda, R., Watanabe, K., \& Ozasa, T. (2019). A Correspondence analysis of seventeen Japanese historical third-year English-as-a-foreign-language textbooks. International Journal of Learning, Teaching and Educational Research, 18(4), 102-134. doi:10.26803/ijlter.18.4.2

Beh, E. J., \& Lombardo, R. (2014). Correspondence analysis: Theory, practice and new strategies. Chichester, West Sussex: Jon Wiley \& Sons.

Clausen, S. E. (1998). Applied correspondence analysis: An introduction. California: Sage Publications.

Fukui, M. (2011). Shakai sisutemu bunseki notameno togouka puroguramu 14: Koresupondensu bunseki, suryoka IIIrui [Multi-purpose program for social system analysis 14: Correspondence analysis, quantification method type III]. Keiei Kenkyu (Fukuyama Heisei Daigaku Keiei Gakubu Kiyo) [Bulletin of Faculty of Business Administration, Fukuyama Heisei University], March 7, 2011, 85-97.

Fukui, M., \& Watanabe, K. (2019a). Tekisuto CR bunnseki no gosuu chouseihou to tango no sentaku: Senyou puroguramu no kaihatu [Number adjustment and selection of words for textual analyses with correspondence analysis: Development of a special program]. ICTATLL, Japan Workshop, Prompt report, March 13, 2019, 1-8.

Fukui, M., \& Watanabe, K. (2019b). Koresupondensu bunseki o mochiita eibun tekisuto bunrui niokeru gosuchoseiho to tango no sentakukijun [Method of word count adjustment and word selection criteria for English text classification using correspondence analysis]. Keiei Kenkyu (Fukuyama Heisei Daigaku Keiei Gakubu 
Kiyo) [Bulletin of Faculty of Business Administration, Fukuyama Heisei University], March 15, 2019, 63-78.

Greenacre, M. (2010). Correspondence analysis of raw data. Ecology, 91(4), 958-963. doi:10.1890/09-0239.1

Greenacre, M. (2017). Correspondence analysis in practice, $3^{\text {rd }} e d$. (Chapman \& Hall/CRC Interdisciplinary statistics). Boca Raton, FL: CRC Press.

Honda, R., Asai, T., Watanabe, K., \& Ozasa, T. (2018). A correspondence analysis of seventeen Japanese historical English-as-a-foreign-language textbooks. International Journal of Learning, Teaching and Educational Research, 17(11), 102-134. doi:10.26803/ijlter.17.11.8

Honda, R., Asai, T., Watanabe, K., \& Ozasa, T. (2019). A correspondence analysis of twelve Japanese historical fifth-year English-as-a-foreign-language textbooks. International Journal of Learning, Teaching and Educational Research, 18(12), 79-100. doi:10.26803/ijlter.18.12.6

Honda, R., Watanabe, K., \& Ozasa, T. (2017). A correspondence analysis of nine Japanese historical English-as-a-foreign-language textbooks. International Journal of Learning, Teaching and Educational Research, 16(10), 100-113. doi:10.26803/ijlter.16.10.8

Ozasa, T. (2003). Meiji, Taisho, Showa-shoki no eigo kyokasho no keiryouteki bunseki [A quantitative analysis of Japanese historical EFL textbooks published in the Meiji Era (1868-1912), the Taisho Era (1912-1926) and the Early Showa Era (1926-1945)]. Research report of the Grant-in-aid for Scientific Research (KAKENHI), Japan Society for the Promotion of Science (JSPS), 2000 - 2002, Basic Research (C) (1) 12680269.

Ozasa, T. (2005). Meiji, Taisho, Showa-shoki no eigo kyokasho no keiryouteki bunseki [A quantitative analysis of Japanese historical EFL textbooks published in the Meiji Era (1868-1912), the Taisho Era (1912-1926) and the early Showa Era (1926-1945)]. Research report for the Grant-in-aid for Scientific Research (KAKENHI), Japan Society for the Promotion of Science (JSPS), 2003 - 2004, Basic Research (C) (1) 15520358

Ozasa, T., \& Erikawa, H. (Eds.). (2004). Eigo Kyokasho no Rekishiteki Kenkyu [A Historical Study of [Japanese] English Textbooks]. Tokyo: Jiyusha.

Ozasa, T., Watanabe, K., \& Fukui, M. (2016). Development of a readability index attuned to the new English course of study of Japan (4): Development of Ozasa-Fukui Year Level, Ver. 3.5nhnc1-6. Conference Proceedings, ICSSB (International Conference on Social Sciences and Business), Tokyo, Japan, August 25-27, 2016, pp. 385-394.

Ozasa, T., Kawamura, K., Umamoto, T., \& Matsuoka, H. (2018). 1900-1908nen shuppan no shogakko eigo kyokasho 4 shu to genko chugakko kyokasho no taiobunseki [Correspondence analysis of four Japanese primary school EFL textbooks published during 1900-1908 and a current junior high school textbook]. Journal of ICTATLL (ICT in the Analysis, Teaching and Learning of Languages), Japan, 57-68.

Sakamoto, M., Watanabe, K., \& Ozasa, T. (2017). A Correspondence analysis of five Japanese historical English-as-a-foreign-language textbooks. Conference Proceedings of ICSSB (International Conference on Social Science and Business), Okinawa, Japan, July 25-27, 2017, pp. 132-144.

Tabata, T. (2005). Profiling stylistic variations in Dickens and Smollett through correspondence analysis of low frequency words. Proceedings of the International Conference on Humanities Computing and Digital Scholarship, 17th Joint International Conference, University of Victoria, June 15-18, 2005, pp. 224-226. 
Takanashi, T. (2018). A quantitative descriptive analysis of Japanese EFL learners' inability to select the correct English articles. JACET (Japan Association of College English Teachers) Chugoku-Shikoku Chapter Research Bulletin, 15, pp. 1-17.

Tono, Y. (2000). A Corpus-based analysis of interlanguage development: Analysing partof-speech tag sequences of EFL learner corpora. In B. Lewandowska-Tomaszczyk, \& P. J. Melia (Eds.), Proceedings of PALC' 99: Practical Applications in Language Corpora, University of Lodz, Poland, April 15-18, 1999, pp. 323-340.

Uenishi, K. (2018). Correspondence analysis of teaching materials and potential relationships between the materials and student awareness. Proceedings of ICEPL (International Conference on Education, Psychology, and Learning), Tokyo, Japan, July 30-August 1, 2018, pp. 158-171.

Van de Geer, J. P. (1993). Multivariate analysis of categorical data: Data applications. Newbury Park, California: Sage Publications.

Watanabe, K., Asai, T., \& Ozasa, T. (2017). A correspondence analysis of five Japanese historical English-as-a-foreign-language textbooks. Conference Proceedings, ICEPL (International Conference on Education, Psychology, and Learning), Sapporo, Japan, August 23-25, 2017, pp. 61-73.

Watanabe, K., \& Fukui, M. (2018a). Quantitative analysis of initial stage English textbooks in Asia in comparison with textbooks in Japan. Conference Proceedings of 2018 International Symposium on Teaching, Education, and Learning, Summer Session, August 22-24, 2018, Waseda University, Tokyo, pp. 373-386.

Watanabe, K., \& Fukui, M. (2018b). Quantitative analysis of initial stage English textbooks in Asia in comparison with textbooks in Japan. Conference Proceedings of 2018 International Symposium on Teaching, Education, and Learning, Winter Session, Okinawa, Japan, January 23-25, 2018, pp. 117-130.

\section{Appendix 1}

Two contrasting textbooks in the values in Dim 1(difficult(+) vs. easy (-) texts)

HIRATSUKA ETCHU-NO-KAMI, a daring man, who feared nothing, while wandering about the country as a knight-errant, was urged by messengers from IEYASU to enter his service. "IEYASU is stingy," he replied; "although he uses polite language to his subordinates, the emoluments he bestows are very scanty."

(Dening-5, 2nd passage (The most difficult))

You are a girl. You are Betty Smith. You are a boy. You are Jack Jones. Are you Betty? Yes, I am Betty. Are you a schoolgirl? Yes, I am a schoolgirl. Are you a teacher? No, I am not a teacher. Are you Tom? No, I am not Tom. Are you Jack? Yes, I am Jack. Are you a schoolboy? Yes, I am a schoolboy.

(Jack\&Betty-1, Unit 1, Lesson 2 (The easiest)) 


\section{Appendix 2}

Two contrasting textbooks in the values in Dim 2(artificial-sounding $(+)$ vs. natural sounding(-) texts)

You have a book.

Have you a book?

Yes, I have.

You have a pencil.

Have you a pencil?

Yes, I have.

You have a card.

Have you a card?

Yes, I have.

(Pacific-1, Lesson 3 (The most artificial-sounding)

This is a big rat.

Can the dog get the rat?

The dog can get the rat.

(National-1, Lesson 3 (The most natural-sounding)

\section{Appendix 3}

Two contrasting textbooks in the values in Dim 3(dialogue-based(+) vs. passage-based(-) texts)

This is a boy and his dog.

Can the boy and his dog run fast?

Yes. See them run.

He cannot run as fast as his dog.

Run, boy, run!

(Choice-1, Lesson 12 (12/53 Lessons) (The most dialogue-based))

T: Is this a cap or a hat?

$P$ : It is a hat.

T: Is this my hat?

$P:$ Yes, it is your hat.

T: Is this your hat?

$P:$ No, it is not my hat. It is your hat.

(Drill-1, Lesson 9 (9/39 Lessons) (The most passage-based))

Jack and Betty are pupils of the $2 A$ class. Mr. Johnson is their teacher. There is a large blackboard in their classroom. There is a teacher's desk in front of the blackboard. Thirty-five pupils' desks and chairs are in the room. In one corner of the room there is a bookcase. And near the windows there are some flower-pots. There is a cage in the hall just outside the classroom. Some little birds are in the cage. There are seventeen boys and eighteen girls in the class. They always help their teacher.

(Jack\&Betty-2, Lesson 2(2/24 Lessons) (The most passage-based)) 


\section{Appendix 4}

Two contrasting textbooks in the values in Dim 4(dominance $(+)$ vs. non-teacher dominance(-) texts)

See the big hen.

See the fat pig.

See the big fat hen.

See the big fat pig.

Do you see the big hen?

Yes, I see the big hen.

Do you see the fat pig?

Yes, I see the fat pig?

The big hen and the fat pig run.

Run, boy, run!

(Choice-1, Lesson 4 (4/53 Lessons) (The most teacher-dominated))

A dog. I have a dog. His name is Tom. He is an old dog. I play with Tom. Tome plays with me. Tom and I play together.

(Globe-1, Lesson 4 (4/24 Lessons) (The least teacher-dominated)) 